\title{
Sin poder, pero con armas Esclavitud y cognición en El amante liberal, de Miguel de Cervantes
}

\author{
Cornelia Ruhe*
}

\begin{abstract}
En effet, tous ces soins sont des choses infâmes. Sommes-nous chez les Turcs pour renfermer les femmes?

Car on dit qu'on les tient esclaves en ce lieu, Et que c'est pour cela qu'ils sont maudits de Dieu.
\end{abstract}

(MOLIÈRE, L'école des maris ${ }^{1}$ )

Desde tiempos inmemoriales, el harén ha sido un lugar predestinado en el que las fantasías eróticas europeas podían desplegarse a sus anchas. Aunque solamente muy pocos europeos tuvieron acceso a serrallos auténticos, hasta entrado el siglo XX la literatura y la pintura los imaginaron como lugares repletos de lascivia, desnudez y, potencialmente, también de sexualidad femenina homoerótica. Una parte imprescindible de estas imágenes la conforma el que la entrada legal a estos lugares estuviera prevista solamente para dos categorías de hombres: por un lado, los «propietarios» de los respectivos harenes y, por otro, los eunucos, que no constituían en modo alguno un peligro para las virtudes de las mujeres.

Esta imagen, sin embargo, está marcada por una clara separación de los mundos cristiano e islámico, en la que los respectivos conocimientos concretos del otro se ven superados por pertinaces prejuicios, por prejuicios que, desde el siglo XVIII se nutrían, no en último término, de la popularidad de la traducción de Galland de los cuentos de Las Mil y Una noches.

* Universidad Mannheim.

1. Molière, L'école des maris, Act I,2. 
La novela ejemplar de Miguel de Cervantes que analizo aquí, de principios del XVII, pertenece a otro tiempo en el que, por razones históricas, las interacciones entre el Cristianismo y el Islám eran mucho más comunes. Muchos cristianos españoles conocían el Oriente por experiencia propia y estaban, por tanto, informados sobre los hechos reales en la sociedad islámica. En algunos casos, este conocimiento se adquiría de modo más bien involuntario, por ejemplo a través del cautiverio tras ser abordados por corsarios musulmanes. Esto, es bien sabido, también le sucedió a Cervantes, quien, tras ser apresado por piratas, pasó los años que van de 1575 a 1580 como esclavo cristiano en Argel. Cervantes, por tanto, conoció la realidad cotidiana de la sociedad islámica. Para él, al contrario que en las representaciones de los siglos posteriores, el harén es un lugar profano para el mantenimiento temporal o duradero de mujeres. En la novela ejemplar que analizo, Cervantes utiliza el setting oriental para cuestionar las representaciones convencionales de matrimonio, género, masculinidad y feminidad, individuo y libertad. Está pues en una misma línea con sus otros textos. Al contrario que otros textos contemporáneos, en El amante liberal Cervantes no establece ninguna oposición entre el mundo islámico y el cristiano, sino que más bien sugiere sutilmente su paralelismo. A continuación se profundizará en esta lectura y se extraerán sus consecuencias tanto para la interpretación del título de la novela como para su contenido ejemplarizante. Se mostrará que el discurso oficial contemporáneo sobre amor y matrimonio es analizado en contraposición a su equivalente en el mundo islámico, adquiriendo un nuevo significado ${ }^{2}$.

De entre todas las novelas ejemplares, tratadas repetidas veces por la crítica, El amante liberal es una de las que menos atención ha recibido. Las dificultades de los críticos con el texto parecen surgir ya en su clasificación: en algunas ocasiones - no sin razón - se ha contemplado como imitación de una novela bizantina ${ }^{3}$, mientras que unos la consideran una de las novelas tempranas de la colección, otros la sitúan entre las más tardías (con lo que se establecen relaciones entre los primeros textos, realistas, y los posteriores, idealistas $)^{4}$, y tampoco falta quien la lee como un texto postcolonial avant la lettre ${ }^{5}$. Con todo, en la mayoría de los casos hay acuerdo en un punto: la

2. La investigación aquí presentada fue enviada a imprenta a principios de 2010, de manera que el libro de Francisco Márquez Villanueva, Moros, moriscos y turcos de Cervantes. Ensayos críticos, Barcelona, Edicions Bellaterra, 2010, 496 pp., no pudo desgraciadamente ser tenido en cuenta.

3. P.ej. Zimic, Stanislav, Las novelas ejemplares de Cervantes, Madrid, Siglo veintiuno de España editores, 1996, 407 pp. Aquí pp. 63 y ss. Vid. también el detallado análisis sobre los distintos tratamientos que han recibido las novelas hasta la fecha, en von Koppenfels, Martin, «Die Ökonomie der Jungfräulichkeit. Psychoanalytische Bemerkungen zu Cervantes' Novelle El amante liberal», Ehrlicher, Hanno/Poppenberg, Gerhard (Eds.), Cervantes' Novelas ejemplares im Streitfeld der Interpretationen, Berlin, Tranvia, 2006, 384 pp. Especialmente pp. 320-322.

4. Esta última es la posición que adopta p. ej., El Saffar, Ruth, Beyond Fiction. The Recovery of the Feminine in the Novels of Cervantes, Berkeley, University of California Press, 1984, 233 pp., p. 12.

5. Vid. al respecto Grünnagel, Christian («Postcolonial Studies für die Prämoderne? El amante liberal unter Orientalismusverdacht», Ehrlicher/Poppenberg, 2006, pp. 337-353), quien comienza prometedoramente notando que el orientalismo se basa en binarismos construidos por Occidente; 
poca calidad de esta novela ${ }^{6}$. Más frecuentemente incluso que en muchas de las novelas ejemplares restantes, los protagonistas de El amante liberal pasan de una aventura a otra sin dejar al lector apenas tiempo para respirar. Esta sucesión aparentemente aleatoria e hipertrófica de escenas ha tenido como consecuencia que el texto haya perdido el favor de la crítica frente a las otras novelas, con más tendencia a la reflexión.

En lo que sigue, intentaré mostrar que la apreciación negativa de la novela, más allá de los aspectos mencionados, está en relación con la simplificadora matriz de lectura a la que muchas veces son sometidos estos textos. En la bibliografía, éstos son tratados frecuentemente como «tridentinisch inspirierte Ehepropaganda» (propaganda matrimonial de inspiración tridentina), para decirlo en la fórmula, en ciertos puntos acertada pero también simplificadora, de Bernhard Teuber ${ }^{7}$. Esta descripción es acertada para determinadas facetas de la mayoría de las novelas ejemplares, pero desvía la atención de otros aspectos de estos complejos textos, como por ejemplo del hecho de que, en algunos de ellos, el matrimonio no desempeñe ningún papel ${ }^{8}$. El sistema de valores ha caído en desorden por el efecto de individuos indómitos: El lector puede buscar únicamente la disolución de este caos inicial en el orden (desembocante, por lo general, en el matrimonio) de la norma aprobada por la familia patriarcal, la Iglesia y la sociedad. Esto sería, sin embargo, una lectura harmonizante del texto, que pasa por alto fácilmente que tras o bajo él se esconden elementos subversivos que desbaratan el enunciado superficial, «verdadero», del texto 9 .

lamentablemente él mismo cae en estos binarismos. Nos ocuparemos de ello con más detalle más abajo, en la nota 21 .

6. Jennifer Lowe p. ej. habla de que «[t]he paucity of critical material on this novela must, to a certain extent, be taken as indicative of its relative lack of value. [...] its various defects and its failures to make any real impact» («A note on Cervantes' El amante liberal», Romance Notes, 12, 1971, pp. 400-403. Aquí p. 400). Vid. al respecto también Clamurro, William, Beneath the Fiction, Frankfurt/ Main, Peter Lang, 1997, 317 pp. Aquí p. 41 así como el resumen de la crítica hasta la fecha, en Ángel Vázquez, Miguel («Mahamut, el buen salvaje: Nacionalismo y maurofilia en El amante liberal de Cervantes», Romance Languages Annual, n. ${ }^{\circ}$ 7, 1995, pp. 642-646. Aquí p. 642) o también Aylward, Edward T., The Crucible Concept. Thematic and Narrative Patterns in Cervantes' Novelas ejemplares, Madison/London, Fairleigh Dickinson University Press, 1999, 327 pp., pp. 94-97.

7. Teuber, Bernhard, «Die Evidenz des blutigen Leibes und das christliche Imaginarium in $L a$ fuerza de la sangre. Plädoyer für eine theopoetische Lektüre einer cervantinischen Novelle», Ehrlicher/ Poppenberg, 2006, pp. 68-106. Aquí p. 83.

8. También Martin von Koppenfels parte de la base de que las novelas ejemplares, en su mayoría, son «inhaltlich [...] bestimmbar als Vorgeschichte einer Ehe, in Gestalt der Trennung und Wiedervereinigung eines heterosexuellen Paares, von dem zumindest ein Teil (der weibliche) überirdisch schön ist». Koppenfels, 2006, p. 321. Esta constatación es, al igual que la de Teuber, sorprendente sobre todo porque en la colección hay dos novelas ejemplares, El licenciado Vidriera y Rinconete y Cortadillo, en las que el tema del matrimonio ni juega un papel ni es relevante.

9. Vid. al respecto p. ej. Ruhe, Cornelia, «Prekäre Exemplarität. Geschlechterkonfigurationen in Las dos doncellas von Miguel de Cervantes», Romanische Forschungen 119, 3, 2007, pp. 317-345, así como Ruhe, Cornelia, «Die Möglichkeiten des Wiewohl. Das Dekret Tametsi und Cervantes’ Novelas ejemplares», von Kulessa, Rotraud/Leuker, Tobias (Eds.), Nobilitierung versus Divulgierung, München, Martin Meidenbauer, 2011, 280 pp., pp. 183-196. 


\section{Contenido}

En primer lugar un breve resumen de la novela. Representa, de modo casi ideal, la rapidità de textos literarios, tal y como la caracterizó Italo Calvino en su segunda conferencia de Harvard:

[...] gli avvenimenti, indipendentemente dalla loro durata, diventano puntiformi, collegati da segmenti rettilinei, in un disegno a zigzag che corrisponde a un movimento senza sosta ${ }^{10}$.

La historia comienza con la queja del joven italiano Ricardo, quien estando preso en la ciudad chipriota de Nicosia, entra en conversación con el renegado Mahamut y le cuenta su historia.

En su patria siciliana, Ricardo estaba enamorado de la bella Leonisa, quien, por su parte, solamente tiene ojos para el afeminado Cornelio. Cuando Ricardo se entera de un encuentro entre ambas familias, corre furioso hacia ellos y les pide cuentas. En este momento, aparece un grupo de corsarios que apresa a Leonisa, Ricardo y a otros. La compra inmediata de la libertad fracasa y los presos son repartidos entre los dos capitanes corsarios. Mientras Yzuf mantiene a Leonisa por su belleza, Fetala se conforma con los hombres, en especial dos corsos particularmente bellos. Cuando los barcos parten de nuevo, se topan con una tormenta en la que el barco de Yzuf naufraga, por lo que Ricardo da por muerta a Leonisa. Ricardo, presa de una inmensa tristeza, es llevado a Chipre, donde es vendido al nuevo bajá de Nicosia. Aquí termina la narración de Ricardo.

Comienzan luego, con Ricardo y Mahamut como espectadores, las ceremonias de cambio de gobierno entre el Bajá de Nicosia saliente y el entrante. Mientras los Bajás están sentados en la tienda junto con el Cadí, aparece un judío que quiere vender una «hermosísima cristiana» (Vol. I, p. 157) que no es otra que Leonisa. Los tres musulmanes presentes quedan prendados de su deslumbrante belleza y quieren comprarla. Es, sin embargo, el Cadí quien mediante una estratagema logra quedarse con la cristiana mientras que los bajás pagan por ella en nombre del Gran Turco. El Cadí la lleva a su harén, donde queda bajo la égida de su mujer Halima, una renegada griega.

Mahamut se encarga de que también Ricardo pase al servicio del Cadí. Ricardo y Mahamut le convencen de que embarque con ellos en dirección a Constantinopla, haga parecer que Leonisa ha fallecido en el barco y, así, pueda adquirirla. Lo que pretenden en secreto es apoderarse del bajel y huir hacia Italia. También Halima, que siente atracción por Ricardo, se embarca.

Tras una serie de batallas navales - ambos beis han enviado sus naves para secuestrar a Leonisa - en el transcurso de las cuales, curiosamente, los turcos se destruyen unos a otros, Ricardo y Mahamut logran apoderarse de

10. Calvino, Italo, Lezioni americane. Sei proposte per il prossimo millennio, Milano, Garzanti, 1993 , p. 43. 
uno de los barcos y ponen rumbo a Italia. Halima viaja con ellos, pues aún alberga esperanzas de conquistar a Ricardo.

Al llegar a Trápana, Ricardo pronuncia frente a los padres de Leonisa un noble discurso en el que renuncia a Leonisa y la cede voluntariamente a Cornelio. Inmediatamente corrige sus palabras y añade que, por supuesto, él no puede decidir por Leonisa, que es dueña de sí misma y que es por tanto ella misma quien, en común acuerdo con sus padres, debe decidir. La libera, pues, y Leonisa se decide por él, por gratitud. Halima, convertida al cristianismo, se casa con Mahamut, ya que Ricardo ya no está disponible.

Para facilitar la orientación en este texto «rápido», en el sentido en que emplea el término Calvino, y facilitar la comprensión de mis disquisiciones posteriores, puede servir el siguiente esquema:

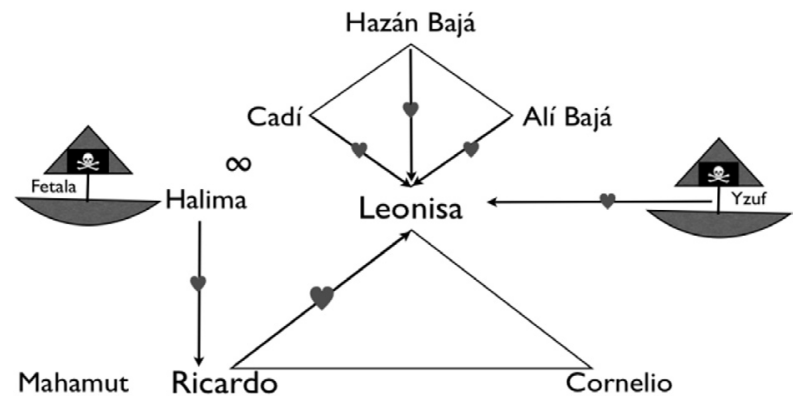

\section{VUELTA A CASA Y SUBORDINACIÓN}

La bibliografía sobre el tema suele tratar, centrándose preferentemente en Ricardo, las numerosas aventuras de los protagonistas como exteriorizaciones de aquellas debilidades que tienen que superar ${ }^{11}$. Así, están en primer plano tanto la evolución de la ligereza juvenil a la razón adulta como el camino que va de la infracción de normas cristianas y sociales a la subordinación a ellas ${ }^{12}$.

11. Así p. ej. El Saffar, p. 143. También Thomas Pabon considera los viajes como una «symbolic representation of the baroque ideal of redemption through purification» («Courtship and Marriage in El amante liberal: The Symbolic Quest for Self-Perfectibility», Hispanofila, 26, 1982, pp. 47-52. Aquí p. 47), mientras que Ali Zaïdi los ve simplemente como un «purification rite» («From Order to Chaos and Back: The Cypriot Voyage in Othello and El amante liberal», Wallace, Paul (Ed.), Visitors, Immigrants and Envaders in Cyprus, Albany/New York, Institute of Cypriot Studies, 1995, 201 pp. Pp. 135-141. Aquí p. 138).

12. También Küpper parte de la base que «es [...] stets von Beginn an absehbar [...] ist, daß am Ende die Dinge wieder so geordnet sein werden, wie sie es vor Einsetzen der Abenteuer gewesen sind» (Küpper, Joachim, «Düstere Welt und lichte Perspektive in den Cervantinischen Novelas ejemplares», Galle, Roland/Behrens, Rudolf [Eds.], Konfigurationen der Macht in der frühen Neuzeit, Heidelberg, Beck, 2000, 356 pp., pp. 167-216. Aquí p. 191) Como se verá, resulta problemático aceptar que el orden se restituye por completo. 
Es cierto, también en el sentido de la cita de Teuber, que en El amante libe$\mathrm{ral}$, al igual que en otras novelas ejemplares ${ }^{13}$, la transformación puede ponerse en relación sobre todo con la actitud frente al matrimonio cristiano: si bien al principio los motivos por los que los personajes quieren casarse no son los adecuados — belleza externa de él o de ella, riqueza, contactos familiares favorables, satisfacción del apetito sexual—, al final, al menos de puertas afuera, hay una conversión hacia los únicos motivos que la Iglesia acepta como legítimos para el matrimonio, a saber «amor compartido [...] sin presencia de la pasión egoísta que sólo busca la satisfacción de los sentidos» ${ }^{14}$. Además, el casamiento generalmente tiene lugar en la forma que lo aprueba el Concilio Tridentino ${ }^{15}$.

Al final de la presente novela tiene lugar incluso una doble boda en la que no sólo Ricardo y Leonisa se unen con la bendición de la Iglesia y la familia, sino en la que también los renegados Mahamut y Halima arriban al puerto del matrimonio bajo la protección del Catolicismo ${ }^{16}$. El propio Ricardo ha sufrido una transformación, pasando de ser un hombre arrogante y demasiado convencido de sí mismo ${ }^{17}$ a ser uno con capacidad de autocontrol y proceder meditado; si al principio ama a Leonisa sin medida alguna y amenaza incluso con infringir los preceptos de la religión, al final se modera ${ }^{18}$. No queda claro, con todo, si cambia también su interés por Leonisa, basado en un principio claramente en la belleza de ésta. Toma nota ciertamente de su «honestidad, su grande valor» (Vol. I, p. 187) pero, igual que antes, sobre todo de su «infinita hermosura» (ibíd.) $)^{19}$.

13. Piénsese p. ej. en La gitanilla, Las dos doncellas, La española inglesa, La ilustre fregona.

14. Cita original: «wechselseitigen Liebe [...] unter Ausschluss der egoistischen Leidenschaft, die auf sinnliche Befriedigung zielt», de «Ehe/Eherecht/Ehescheidung», Krause, Gerhard/Müller, Gerhard (Eds.), Theologische Realenzyklopädie, Berlin/New York, de Gruyter, 1982, t. IX: Dionysius Exiguus - Episkopalismus, pp. 308-362. Aquí p. 325.

15. En efecto, Ricardo y Leonisa se casan al final en presencia de los padres de ella, otros testigos y, con el obispo y el arzobispo, en presencia de las altas esferas eclesiásticas. Gracias a ellos se libran de otro de los preceptos tridentinos, de las amonestaciones: «Hallóse presente el obispo o arzobispo de la ciudad, y con su bendición y licencia los llevó al templo, y dispensando en el tiempo, los desposó en el mismo punto.» (Vol. I, p. 187).

16. Los procesos de la Inquisición referentes a la credibilidad de conversiones fingidas al Islam, es decir, hechas solamente de puertas afuera, pero nunca con convencimiento, eran generalmente largos. El propio Cervantes los tematiza en el Relato del Cautivo así como en Los baños de Argel; en El amante liberal, se solventa con una única frase «Reconciliáronse con la Iglesia, Mahamut y Halima.» (Vol. I, p. 187). Barbara Fuchs cree que esto se debe a que Italia se establece, desde el punto de vista religioso, como un lugar más liberal que España («Passing Pleasures: Costume and Custom in El amante liberal and La gran sultana», Fuchs, Barbara, Passing for Spain, Chicago, University of Illinois Press, 2003, 160 pp., pp. 63-86. Aquí p. 68).

17. La descripción que da Leonisa es: «[...] te hago saber, Ricardo, que siempre te tuve por desabrido y arrogante, y que presumías de ti algo más de lo que debías.» (Vol. I, p. 173).

18. Al principio, Leonisa es para él la única «deidad» (Vol. I, p. 142) más tarde «oscureciendo [no solamente] los rayos del sol si la tocaran sino todo el cielo con sus estrellas» (Vol. I, p. 164). En este punto, es el renegado Mahamut quien le advierte de los peligros del amor desmedido: «[...] a cada paso temo que has de pasar tanto la raya en las alabanzas de tu bella Leonisa, que, dejando de parecer cristiano, parezcas gentil.» (Vol. I, p. 164s.).

19. En realidad, por lo que respecta a «luxuria», Ricardo, al contrario de lo que parezca sugerir el texto, no ha cambiado. Con ello, la figura está en la misma tradición que p. ej. Rodolfo, de La fuerza 
Leonisa, por su parte, a pesar de que esto es algo que se afirma repetidamente en la bibliografía, no cambia. Es consciente del cambio de Ricardo, pero se prohíbe cualquier tipo de declaración amorosa «que ya que soy desamorada, no soy ingrata ni desconocida» (Vol. I, p. 172), tal vez porque la honestidad le prohíbe declarar su amor antes del matrimonio. Por consiguiente, el texto nos dice únicamente que al final acepta la boda con Ricardo solamente por gratitud ${ }^{20}$ y con mucho menos entusiasmo que otras mujeres en las novelas de Cervantes ${ }^{21}$.

Visto con detenimiento, este final es, para una novela ejemplar, poco edificante. Es cierto que el marco de la boda es el adecuado, pero ni el novio ni la novia parecen, pese a todo, tener la actitud adecuada ante semejante momento. No puede hablarse, por tanto, de propaganda matrimonial, si la novia da el sí bajo estas condiciones y algo dubitativa.

La ejemplaridad de la novela, pues, debe buscarse en otro lugar, lugar al que Cervantes, en el título y también en el último párrafo, parece hacer claras referencias: Lo especial en Ricardo sería el hecho que sea un amante liberal que, pese a su amor por Leonisa, está en condiciones de asumir la decisión de ésta a su favor o en su contra.

Merece la pena observar más de cerca el momento de la decisión: Ricardo se da cuenta de que Leonisa no es posesión suya y que, por tanto, no puede disponer a placer sobre ella sino que, al contrario, es ella misma la única que - excepción hecha de sus padres - decide sobre su vida.

Esta posición es extraña en el Siglo de Oro, más aún si quien la adopta es un hombre. Si el carácter ejemplar de la novela radica en esta afirmación del derecho de la mujer a la autodeterminación, es necesario comprender el modo en que Ricardo puede llegar a tal «final epiphany» ${ }^{22}$.

de la sangre. Ninguno de los dos cumple con la tesis de Küpper de la presencia de «Affektenkontrolle» a lo largo del texto (Küpper [2000], p. 195). El propio Küpper lo nota más adelante (p. 201), pero no extrae de ello las consecuencias necesarias para su interpretación. Ampliando sus tesis, podría postularse que lo que se trata en las novelas ejemplares no es tanto el control de los afectos por el propio individuo, sino de la recondución de estos afectos hacia cauces aprobados por la sociedad (y por terceros). Pero con esto no se solucionan de forma duradera los problemas que surgen de la decadencia afectiva del individuo sino que, como mucho, se aplazan temporalmente. Küpper cree que la codicia sensual de Rodolfo por Leocadia se transforma en una conducta legítima a través del matrimonio y gracias a él (p. 203). En la época postridentina, sin embargo, la esencia del matrimonio no consistiría precisamente en la satisfacción de la codicia sexual.

20. Sears y Aylward notan también la aceptación poco efusiva de Leonisa, sorprende, sin embargo, que Aylward apunte luego que Leonisa y Ricardo, al final, están unidos por el amor (Aylward [1999], p. 108).

21. Valgan como ejemplo la gitanilla, protagonista de la novela epónima, o Teodosia en Las dos doncellas.

22. Martín, Adrienne, «Rereading El amante liberal in the Age of Contrapuntal Sexualities», Cruz, Anne y Johnson, Carroll (Eds.), Cervantes and his Postmodern Constituencies, New York/ London, Garland Publishing Inc., 1999, 275 pp., pp. 151-169. Aquí p. 154. 


\section{MATERIALISMO Y SEXUALIDAD}

Tradicionalmente, en la bibliografía sobre el tema, el mundo del amante liberal se contempla como un mundo separado en dos partes distintas, regidas por sus respectivos sistemas de valores. Tendríamos por un lado el contexto cristiano, en el que valores inmateriales como honra, libertad personal y amor sincero tienen una gran importancia; en el otro, estarían los musulmanes, para quien, según la bibliografía, únicamente tendrían importancia los valores materiales y económicos ${ }^{23}$.

A favor de los intereses económicos de los protagonistas hablan en la novelas ciertas cifras: ininterrumpidamente se nombran cantidades e importes, se cambian, se discuten, se pagan, montos ellos con los que se cifra el valor de los esclavos cristianos, en especial el de Ricardo y el de Leonisa. El valor de esta última resulta siempre más alto que el de Ricardo: en un principio, los corsarios piden 6.000 y 4.000 escudos por sus presos, luego bajan a 5.000 y 3.000 respectivamente, siempre y cuando, eso sí, se demuestre que Leonisa es virgen; de no ser así, su precio caería drásticamente, hasta los 300 ó 400 escudos. Que la propia Leonisa emplea los mismos criterios se ve en el hecho que se moleste cuando Mahamut miente, diciéndole que Cornelio quería ofrecer por ella solamente 300 ó 400 escudos.

No son, como han pretendido algunos críticos, los intereses económicos los que nos permiten trazar una línea divisoria entre el mundo cristiano y el musulmán, sino el modo en que se vive el deseo sexual —en especial el femenino-. Para los musulmanes, así en la obra, uno de los valores potenciales de las esclavas cristianas es el de poder ser útiles a sus poseedores y poseedoras en el cumplimiento de sus deseos sexuales. Así por ejemplo, el hecho de que Fetala, el capitán del segundo galeón corsario, cambie voluntariamente a Leonisa por unos presos masculinos, en especial por los ya nombrados corsos, sugiere que está más interesado en hombres jóvenes que en mujeres ${ }^{24}$. Los dos Bajás y el Cadí no quieren adquirir a Leonisa para ofrecerla al Gran Turco, sino para convertirla en su amante. En estos casos, sin embargo, se mantiene el orden tradicional cristiano de los sexos. El verdadero escándalo está en otro hecho: una mujer, la renegada Halima, muestra sin tapujos su interés sexual por Ricardo y lo persigue con tesón.

Tanto en el Imperio Otomano como en el Cristiano, la presión social y la económica van de la mano; en palabras de Mahamut: «todo se vende y todo se

23. Grünnagel (2006) comienza explicando el Orientalismo tomando como punto de partida un binarismo creado en Occidente, pero en lo siguiente cae en la propia trampa del binarismo. Para él, el Oriente de la novela se convierte en un «frühneuzeitlichen Empire of Evil der Novelle» (p. 344), éste «erfüllt die Funktion, ein Gegenbild zum Okzident vorzustellen» (p. 345); también Zaïdi (1995) parte de un «clash between different cultures and value systems» (p. 136); vid. al respecto también Pabon (1982), p. 47.

24. Esta impresión se refuerza si uno piensa p. ej. en los dos esclavos cristianos de Los baños de Argel: su señor musulmán intenta convertirlos por todos los medios y en el texto queda bastante claro que la conversión no tendría lugar solamente en sentido religioso, sino que sería también una conversión a la homosexualidad. Cuando uno de los dos jóvenes se niega vehementemente, su señor lo crucifica. 
compra» (Vol. I, p. 141). Así por ejemplo, cuando el comerciante judío vende a Leonisa, lo hace porque ésta se le ha resistido: si de ella no puede obtener ganancias sexuales, al menos quiere lograr provecho económico. Con Hazán y Alí ocurre al revés: prendados como están, se muestran inmediatamente dispuestos a invertir fuertes sumas en conseguirla.

El mundo musulmán de la novela ejemplar es, citando a Murillo «a culture whose sexual mores are diametrically opposed to their Catholic culture [se habla de los presos] $\gg^{25}$. Consecuentemente, el mundo cristiano se contempla como más elevado, moralmente hablando, y no como algo orientado a la realización de los deseos sexuales o deseos materiales. De este modo, es precisamente la oposición con la decadencia mundana y material del mundo musulmán la que permite a las virtudes de los cristianos y su mundo aparecer con claridad ${ }^{26}$. No comparto esta opinión. Mi tesis es, más bien, que el contexto musulmán en el que los protagonistas se ven situados de modo repentino se presenta de forma sutil como equivalente al cristiano ${ }^{27}$. La única diferencia parece residir en el modo en que se trata a la figura de Ricardo: se convierte, de repente, en lo que anteriormente, desde su perspectiva, sólo eran las mujeres - una mercancía, no sólo en el sentido económico sino también en el sexual.

En otras novelas ejemplares, Cervantes también presenta el mundo cristiano como movido por intereses económicos muy concretos. Preciosa, la figura femenina de La gitanilla, sabe perfectamente que, si quiere alcanzar una posición social, en las negociaciones con potenciales maridos debe vender su belleza y su virginidad (que ella misma califica de vendible) al mejor postor. En este sentido, El amante liberal podría interpretarse casi como continuación de esta novela que la precede en la colección, ya que aquí se da con detalle el valor comercial de la virginidad. La bella dama pasa, en este caso, de tener un valor de 5.000 escudos a valer sólo 300 ó 400. En la práctica totalidad de

25. Murillo, L. A., «Narrative Structures in the Novelas Ejemplares: An Outline», Cervantes: Bulletin of the Cervantes Society of America 8,2, 1988. pp. 231-250. Aquí p. 241. Es la misma posición que también defienden p.ej. Thomas Pabon, quien habla del «corrupt, hedonistic world of the Turks» (Pabon [1982], p. 48) así como, Ali Zaïdi, para quien el mundo muslmán está repleto de «mendacity and corruption» (Zaïdi [1995], p. 138).

26. Es también la postura que adopta Grünnagel (2006), quien consecuentemente, elimina de su interpretación todas las ambivalencias en la representación del mundo musulmán. Zaïdi (1995) y Pabon (1982) también contemplan el Chipre musulmán como un mundo en el que «the refinements of civilization are eclipsed by primal urges» (Zaïdi [1995], p. 141).

27. Barbara Fuchs es la única, según creo, que defiende una postura semejante. Ella nota que Cervantes, en la novela, expone repetidamente el paralelismo de ambos mundos a través de disfraces «The narrative does more than simply challenge the absolute distinctions between Christians and Turks by stressing the porosity of borders in the eastern Mediterranean; it also mounts a critique of Spanish empire in disguise by transforming the trope of cross-cultural transvestism into a powerful ironic device. The characters' more or less conventional impersonations prepare the reader for the ironic interchangeability on which that critique depends: if a Christian can pass for Turk or a Turk for Christian, then attacks on the Turks may just as easily disguise attacks on Christian - and, more specifically, Spanish - practices.» (Fuchs [2003], p. 64). Con esto, es también una de las pocas que ofrece una interpretación satisfactoria de la escena de disfraces que aparece al final de la novela y que, normalmente, suscita en la crítica reacciones de extrañeza. 
las novelas ejemplares, la riqueza de los pretendientes masculinos es un tema tan destacado como la belleza y atractivo sexual de las mujeres ${ }^{28}$; son las dos caras de una relación económica de cambio aceptada como algo completamente normal y que no es presentado, en ningún caso, como inmoral ${ }^{29}$.

Ya desde el mismo momento en el que Ricardo habla de su amor por Leonisa, la belleza desempeña un papel central. En la línea de un amor cortés, se declara preso de su belleza y su voluntad, en la lógica de la retórica que emplea, está sometido, es casi un esclavo, antes de serlo en sentido estricto. Según Ricardo, lo único que le mueve es el amor a su belleza, mientras que lo que mueve a Leonisa y a sus padres son los intereses económicos, ya que si le permiten que se postule como amante es a causa de su riqueza. Cuando Leonisa se fija en Cornelio, sus padres tampoco se muestran contrarios a ello, ya que Cornelio es «de mejor condición» (Vol. I, 143) que Ricardo, es decir, es, en términos económicos, el mejor partido. Es cierto, por una parte, que (aún) no se nombran cifras sobre el valor de Ricardo, Cornelio o Leonisa, pero se percibe que el entramado de intereses sexuales y económicos se da tanto entre los musulmanes, cuya moral es supuestamente reprochable, como entre los cristianos.

Leonisa es la mercancía que sus padres pretenden vender al mejor postor y cuyo valor se mide en su belleza y su virginidad; Ricardo, por su parte, quiere emplear su riqueza para apoderarse de su bello cuerpo ${ }^{30}$. Para desfogarse contra Cornelio, competidor de mayor riqueza, lo tacha de débil afeminado, es decir, lo descalifica en su masculinidad y su potencia sexual. La única diferencia clara entre este proceso en el campo de acción islámico es que los pretendientes no muestran abiertamente sus cartas sino que actúan bajo el manto del amor romántico, un amor que, en Cervantes, sólo puede (y quiere) tapar a medias los claros intereses económicos y sexuales. Cervantes muestra la mentalidad posesiva de Ricardo de modo transparente a través del comerciante judío: no es sólo que Ricardo se sienta abrumado con Leonisa «de ver andar en almoneda su alma» (Vol. I, 160), lo que le aflige especialmente es tener que perder su «querida prenda» ${ }^{31}$.

En este contexto, solamente puede calificarse de consecuente el hecho de que Leonisa apenas cambie en el transcurso de la novela, hecho al que, por

28. Piénsese p. ej. en El celoso extremeño, Las dos doncellas o en La española inglesa. En todas estas novelas, quizá de modo especial en Las dos doncellas, las mujeres tematizan abiertamente la riqueza de los potenciales maridos; una gran riqueza se contempla como una razón legitima para preferir uno al otro.

29. Vid. al respecto también Xuan, Jing, «Der Chronotopos des Geldes - "Vermittlung", "Verhandlung" und "Transkodierung” in La gitanilla», Ehrlicher/Poppenberg, 2006, pp. 178-197.

30. Este aspecto materialista del matrimonio cristiano aparece claramente en las novelas de Cervantes, así que resulta curioso que Thomson-Weightman (1992) diga que Leonisa no se convierte en objeto hasta que cae en el cautiverio turco (p. 68), sobre todo teniendo en cuenta que el artículo, justo antes, lista los motivos económicos de la boda cristiana.

31. Incluso aunque este tipo de expresiones fueran habituales en el cortejo contemporáneo y con ello pudieran ser consideradas como convencionalismos de la época, resulta llamativo lo fuertemente impregnado por el interés económico que se halla este discurso, que sólo puede enmascarar superficialmente dichos intereses que (también) se ocultan tras él. 
cierto, remite el propio Ricardo ${ }^{32}$. Para ella es innecesario someterse a un proceso de transformación ya que tanto la sociedad de la que es raptada como aquella a la que va a parar como esclava operan con los mismos parámetros. En Sicilia, es cierto, Leonisa no es nominalmente una esclava, pero está tan en venta como en Chipre. Sus padres, que complacen sus deseos mientras éstos no se contrapongan a sus propios intereses materiales, se corresponden con los cambiantes dueños que ponen en venta la belleza de Leonisa exponiendo su atractivo sexual.

$\mathrm{Su}$ conocimiento de los fundamentos materialistas de la sociedad cristiana ayuda a Leonisa a desenvolverse en el mundo musulmán: inmediatamente después de que los corsarios la secuestraran a ella y a Ricardo, apenas recuperada del desmayo, oye que van a ahorcar a Ricardo porque, defendiéndola, ha matado a cuatro turcos. Sin dudarlo un instante, hace notar a los secuestradores que hacer eso sería un gran error, ya que Ricardo es muy rico y, de colgarlo, estarían perdiendo la posibilidad de poder exigir un suculento rescate (Vol. I, p. 147), argumento que los turcos acogen de inmediato. Los modelos de conducta que Leonisa ha conocido como operantes en el mundo cristiano pueden trasladarse al mundo musulmán sin que le sea necesario cambiar. Para lo que sigue, como podrá verse, tampoco le resulta necesario aprender nuevas estrategias.

\section{FALTA DE LIBERTAD Y CASTRACIÓN (SIMBÓLICA)}

A Ricardo le sucede algo muy distinto. Mirando hacia atrás, se define también en Sicilia como preso, pero preso de su propia pasión por Leonisa. La ama más allá de los límites razonables y de los autorizados por la Iglesia y, en una exaltación juvenil casi blasfema, la eleva como su diosa. La sirve. Para él, esta prisión resulta una tortura, pero, en comparación, soporta la «esclavitud del amor» sin quejarse demasiado ${ }^{33}$, ya que corresponde a un ideal común.

Tras ser apresado por los corsarios comienza su esclavitud en un sentido estricto, ya no espiritual sino material: se convierte en un esclavo cristiano. Este estado, nuevo en su concreción, es el que le lleva a las largas quejas con las que Cervantes comienza la novela. Ricardo es vendido repetidas veces como mercancía para finalmente, con ayuda de su amigo, el renegado Maha-

32. Con sus palabras, Ricardo vuelve a confirmar de forma implícita el paralelismo del mundo cristiano y el musulmán: «Y aunque las desventuras y tristes acontecimientos suelen mudar las condiciones y aniquilar los ánimos valerosos, no han sido así con el verdugo de mis buenas esperanzas; porque con más valor y entereza que buenamente decirse puede, ha pasado el naufragio de sus desdichas y los encuentros de mis ardientes cuanto honestas importunaciones; en lo cual se verifica que mudan el cielo, y no las costumbres, los que en ellas tal vez hicieron asiento.» (Vol. I, p. 186).

33. Resulta significativo que sea precisamente Mahamut el renegado quien le llame la atención sobre la blasfemia: «[...] detente, amigo Ricardo, que a cada paso temo que has de pasar tanto la raya en las alabanzas de tu bella Leonisa, que, dejando de parecer cristiano, parezcas gentil») (Vol. I, p. 164s.). 
mut, ir a parar a manos del Cadí que también ha adquirido a Leonisa para, según dice, presentársela al Gran Turco.

En realidad, el Cadí aspira a convertir a Leonisa en su amante. A ella, por su parte, estas pretensiones no parecen sorprenderla y, como sabe el lector, ya ha desarrollado una capacidad de defensa ante tales acercamientos a fin de conservar su bien más preciado, su virginidad. No sucede lo mismo con Ricardo, para quien el problema central ya no es ser prisionero sino ser el objeto de deseo de una mujer: Halima, la mujer del Cadí, está convencida de no haber visto «más lindo hombre en toda su vida» (Vol. I, p. 166) y forja junto con su esclava Leonisa planes para convertirlo en su amante. Para Ricardo, ser el objeto de deseo de una mujer es algo completamente nuevo. En esa situación adquiere involuntariamente un papel que en la sociedad a la que pertenece está reservado exclusivamente a mujeres, es decir, sufre un proceso de afeminación y sufre en sus propias carnes aquello que había reprochado a su rival Cornelio. Parece que, junto a su libertad, ahora está también cerca de perder su identidad sexual, hasta este momento incuestionada.

Ricardo y Leonisa cumplen, en bella simetría, la función de mediadores de anhelos ajenos. Tal y como corresponde a la socialización específica de sus respectivos sexos, cada uno maneja la situación de modo distinto. Leonisa lo ve de modo muy pragmático: debe conservar su virginidad puesto que, de lo contrario, su valor de mercado desciende ${ }^{34}$. Ricardo no posee nada de semejante valor que pudiera perder, y por tanto ella le aconseja acceder a los deseos de Halima o, al menos, aparentarlo:

Halima, nuestra ama [...] me ha dicho que te adora; hame puesto por intercesora de su deseo. Si a él quisieres corresponder, aprovecharte ha más para el cuerpo que para el alma; y cuando no quieras, es forzoso que lo finjas, siquiera porque yo te lo ruego y por lo que merecen deseos de mujer declarados (Vol. I, 169).

Leonisa pues, demanda a Ricardo que acepte los deseos de una mujer y contradice con ello, de modo chocante, el orden sexual de su patria común, lo cual permite contemplar a Leonisa desde una nueva perspectiva. Adopta el papel del ama, papel que hasta ahora Ricardo sólo le había otorgado figuradamente.

Los ya mencionados paralelos entre las sociedades cristiana y musulmana pueden comprobarse en ambas figuras femeninas. La mujer que toma decisiones y es activa sexualmente no es una particularidad oriental, sino que ya puede detectarse en Leonisa en su patria. Prefiere a Cornelio, quien no destaca por su masculinidad sino más bien por su comportamiento afeminado, antes que a Ricardo.

34. Es indudable que, en aquel tiempo, la virginidad como precepto religioso se había convertido en convención social. Cervantes, al crear una relación tan estrecha entre el valor de Leonisa - abundantemente cuantificada en el texto- y su virginidad, muestra claramente que bajo ésta última hace tiempo que no se esconden únicamente intereses religiosos. 
Aunque la demanda de Leonisa horroriza a Ricardo, éste se somete a ella y deja las negociaciones ulteriores en sus manos (Vol. I, p. 170). Con todo, si tenemos en cuenta que la figura hasta este momento ha sido caracterizada como vehemente y autoritaria, esta concreta disposición a someterse a ella parece, cuanto menos, extraña. Puede explicarse con su situación especial en esta escena:

Ya sea para actuar como mediador del Cadí o para posibilitar a Leonisa que logre ganarse a Ricardo para Halima, ambos logran independientemente el uno del otro, que Ricardo tenga acceso al harén, privilegio que, como ya hemos dicho, estaba reservado solamente a los propietarios y los eunucos. En este caso, sin embargo, todo ocurre sin problemas ya que, como el narrador ha explicado con anterioridad, a ojos de los musulmanes los esclavos cristianos no son auténticos hombres:

[...] los moros son en extremo celosos y encubren de todos los hombres los rostros de sus mujeres, puesto que en mostrarse ellas a los cristianos no se les hace de mal; quizá debe de ser que por ser cautivos no los tienen por hombres cabales (Vol. I, 166).

Como presos, los esclavos cristianos no son tenidos por «hombres cabales», es decir, completos. Con ello no solamente se les niega su libertad sino sobre todo su masculinidad en sentido estricto: como esclavos son considerados impotentes y con ello su trato con las mujeres es tan inofensivo como el de los eunucos.

También para el propio Ricardo su presencia en harén simboliza, al menos de modo pasajero, una suerte de «amasculinización» ya que, de repente, se encuentra en un interior habitado exclusivamente por féminas. En lugar de suceder como uno podría esperar según el Orientalismo del siglo XIX, es decir, proveyendo sus fantasías eróticas de nuevas imágenes, el harén, descrito aquí sin romanticismo alguno, se convierte para él en un lugar de sumisión a la voluntad de las mujeres, a la de Halima y sobre todo a la de Leonisa en representación de Halima. Las relaciones de poder a las que está acostumbrado se han invertido. La sumisión simbólica se ha convertido en una real y esta nueva situación requiere a su vez nuevos modos de comportamiento.

Al contrario de lo que sucede con Ricardo, Leonisa no necesita mucha orientación, ella ya sabe perfectamente cómo se comporta una subordinada. «Fingimiento y engaño», las armas de los que no tienen poder, deben ser empleados, al menos en lo que a ella se refiere, para mantener a distancia prudente los avances del Cadí y para, finalmente, lograr la fuga del harén. La naturalidad con que se sirve de estos medios, muestra que ya en su patria cristiana éstos le eran familiares, por ejemplo para hacer frente a las avanzadas de Ricardo ${ }^{35}$. Éste, por su parte, aún debe ser instruido en el arte del engaño

35. Küpper ve en el recurso a la hipocresía y el engaño «ein verständliches, moralisch aber problematisches Verhaltensregister» (Küpper [2000], p. 197). Al mismo tiempo, llama la atención 
y la hipocresía, ya que, como hombre, se valía hasta el momento de modos más directos: rabia, furia ${ }^{36}$.

A través de sus experiencias en el cautiverio musulmán, Ricardo recibe una breve pero impresionante lección de lo que significa ser una mujer: experimenta la falta de libertad y la castración simbólica. Se da cuenta de que se ha convertido en el objeto de deseo de una persona por la que él no siente nada en absoluto y, sobre todo, de que, en caso extremo, incluso se puede llegar a disponer (se) de él eróticamente. Sin embargo, también ha visto (y en esto, Leonisa fue su maestra) cómo uno puede librarse de estas imposiciones: con disimulo, mentira y artimañas. Como preso cristiano en territorio musulmán, se ve de repente, en muchos sentidos, relegado a un papel que equivale al de la mujer en la sociedad cristiana. Solo esta experiencia, que podría llamarse transexual, es la que le permite convertirse en un «amante liberal».

\section{LIBERALIDAD E INTERÉS PROPIO}

En este contexto surge la pregunta de cómo Ricardo, una vez de vuelta en Sicilia, aprovecha estos conocimientos adquiridos. A primera vista parece evidente: él, que ha podido ver de modo muy plástico la falta de libertad a la que está sometida la mujer en ambos mundos, libera a Leonisa, declarándola (casi) completamente independiente: «Leonisa es suya, y tan suya, que, a faltarle sus padres [...] ningún opósito tuviera a su voluntad» (Vol. I, p. 186). Esta declaración empática parece convertirlo, de puertas afuera, en un amante liberal, en una suerte de feminista avant la lettre; esta sería la interpretación ejemplar del texto y literal del título.

En mi opinión, sin embargo, el mensaje implícito es otro distinto: en su discurso, Ricardo deja claro que él no tiene el derecho a liberarla ya que ella ya es libre, libre «a faltarle sus padres» (Vol. I, p. 186), quienes asisten a la escena. Como ya se ha mencionado más arriba, los padres reaccionan muy positivamente a cualquier tipo de estímulo material. Esto está relacionado con la manera de proceder de Ricardo: si hasta ahora todos sus intentos de posesión de Leonisa habían sido por la vía directa; sin embargo, su experiencia en Chipre como «mujer» le ha permitido ver que, más que este proceder, para Leonisa cuentan las ataduras y obligaciones a las que está sometida a

sobre el hecho de que en La fuerza de la sangre un hombre, el padre de la deshonrada Leocadia, explica a su hija la doble moral de la sociedad y le aconseja precisamente emplear esa ambigüedad y superficialidad de la moral imperante en propio beneficio para ocultar su deshonra. En mi opinión, el pragmático Cervantes, tal y como Küpper lo designa repetidamente, no está interesado en este contexto en las bases morales del proceder de sus protagonistas sino más bien en reflejar el código moral, que sin duda es hipócrita. En el padre de Leocadia se muestra que en ningún caso son las mujeres las únicas que se sirven de las estrategias de la hipocresía y el engaño, sino más bien todos aquellos que se encuentran en una situación social baja y problemática.

36. Sorprende aquí que Pabon (1982) diga que ambos protagonistas deben ser instruidos en ese arte del engaño que les era extraño a ambos (p. 49). 
causa de convenciones sociales. Como mercancía en un sistema centrado en valores económicos, no está en condiciones de imponer sus ideas sino que está, más bien, obligada a actuar conforme a las reglas implícitas y explícitas de sus padres y de la sociedad que éstos representan. La obligación a mostrarse agradecido por favores recibidos es una de las reglas de esta sociedad orientada al valor de cambio.

El subtexto de la novela, por tanto, burla su interpretación ejemplar: la lección que Ricardo ha aprendido en el harén la emplea para perseguir más eficientemente aún sus propios intereses. Si antes no había logrado ganarse a Leonisa con gestos y amenazas dominantes y masculinas, ahora se vale de los medios que ella misma le había recomendado. Fingimiento y engaño no sólo le ayudan a liberarse de la esclavitud, cautiverio e impotencia simbólica sino sobre todo a dominar exitosamente a la mujer que ama y a obligarla a casarse con él. A aquello que no logró por la vía masculina accede ahora gracias a los conocimientos adquiridos sobre los artificios y artimañas de las mujeres.

Con ello, la afirmación que hace Ricardo de la libertad de Leonisa es a fin de cuentas la cínica confirmación de su falta de libertad, tal y como pone de manifiesto la respuesta que ella le da:

Pues con esa licencia [...] quiero que no se me haga de mal mostrarme desenvuelta, a trueque de no mostrarme desagradecida; y así, joh valiente Ricardo!, mi voluntad, hasta aquí recatada, perpleja y dudosa, se declara en favor tuyo; porque sepan los hombres que no todas las mujeres son ingratas, mostrándome yo siquiera agradecida. Tuya soy, Ricardo, y tuya seré hasta la muerte, si ya otro mejor conocimiento no te mueve a negar la mano que de mi esposo te pido (Vol. I, 187).

Las convenciones, así lo dice ella misma, prohíben a Leonisa mostrarse desagradecida, más aún cuando Ricardo no sólo se presenta como su salvador sino también como su benefactor, que le ha legado todos sus bienes. De que la vida de Ricardo la ha salvado Leonisa gracias a su pragmatismo vital ya no se habla. No decidirse por Ricardo pese a su aparente generosidad la dejaría en mal lugar no sólo a ella misma sino también al resto de las mujeres. Gracias a su habilidosa argumentación, Ricardo logra crear una situación en la que sus propios deseos se verán cumplidos sin tener en cuenta los de Leonisa. Con ello, la liberalidad del amante liberal se revela como una estrategia para lograr recuperar el poder mediante las armas de los que no tienen el poder, de las mujeres. 


\title{
Resumen
}

En la novela ejemplar El amante liberal, Miguel de Cervantes utiliza el setting oriental para cuestionar las representaciones convencionales de matrimonio, género, masculinidad y feminidad, individuo y libertad. Al contrario de otros textos contemporáneos, en El amante liberal Cervantes no establece ninguna oposición entre el mundo islámico y el cristiano, sino que más bien sugiere sutilmente su paralelismo. A continuación se profundizará en esta lectura y se extraerán sus consecuencias tanto para la interpretación del título de la novela como para su contenido ejemplarizante. Se mostrará que el discurso oficial contemporáneo sobre amor y matrimonio es analizado en contraposición a su equivalente en el mundo islámico, adquiriendo un nuevo significado.

Palabras clave: Cervantes, El amante liberal, matrimonio, ejemplaridad, orientalismo, gender.

Title: Powerless but armed. Slavery and cognition in Miguel de Cervantes' El amante liberal

\begin{abstract}
In his exemplary novel El amante liberal, Miguel de Cervantes uses the oriental setting to question the conventional representations of matrimony, gender, masculinity and feminity, individualism and freedom. Unlike other contemporary texts, his novel does not establish an opposition between the Muslim and the Christian world, but instead subtly points to the parallels between the two. In the following, our interpretation will lead to a new understanding of the novel's title as well as of its exemplarity. It will be demonstrated that the official (Christian) discourse of love and matrimony takes on a new meaning when paralleled to its equivalent in the Muslim world.
\end{abstract}

Key words: Cervantes, El amante liberal, matrimony, exemplarity, orientalism, gender. 